\title{
Return of the Man-Machine Interface: Violent Interactions
}

\author{
Duncan Rowland ${ }^{1}$, Conor Linehan ${ }^{1}$, Kwamena Appiah-Kubi ${ }^{1}$ \\ and Maureen Schoonheyt ${ }^{2}$ \\ ${ }^{1}$ University of Lincoln, Brayford Pool, LN67TS, UK \\ \{drowland, clinehan, kappiahkubi\}@lincoln.ac.uk \\ ${ }^{2}$ Hague University of Applied Sciences, Johanna Westerdijkplein 75, The Hague, Netherlands \\ maureenschoonheyt@hhs.nl
}

\begin{abstract}
This paper presents the design and evaluation of "the man-machine interface" a punchable interface designed to criticise and react against the values inherent in modern systems that tacitly favour one type of user (linguistically and technically gifted) and alienate another (physically gifted). We report a user study, where participants used the device to express their opinions before engaging in a group discussion about the implications of strength-based interactions. We draw connections between our own work and that of evolutionary biologists whose recent findings indicate the shape of the human hand is likely to have been partly evolved for the purpose of punching, and conclude by examining violent force as an appropriate means for expressing thoughts and feelings.
\end{abstract}

Keywords: Man-machine interface, punch interface, critical design, values-sensitive design.

\section{Introduction}

This paper presents a project designed to explore, criticise and provoke consideration of values and biases inherent in modern interface design. We propose that communication technologies have become increasingly advantageous to linguistically talented people, to the detriment of those whose strengths lie more in gross motor movements and physical prowess. Further, due to the increasing technological mediation of many aspects of modern life such as work, education, health care, play, socializing, and governance, we are concerned over the potential wide scale disenfranchisement and

Note: This is the author's version of the work. It is posted here by permission for your personal use. Not for redistribution. The definitive version was published as: Rowland, D., Linehan, C., Appiah-Kubi, K., and Schoonheyt, M. (2013). Return of the Man-Machine Interface: Violent Interactions. In proceedings of Advances in Computer Entertainment (Springer), 215-229. 
disillusionment of people whose talents are primarily physical. As a case study, we examine inherent biases in contemporary methods for expressing preferences and opinions. We challenge these biases through the design of a provocative artefact, the "man-machine interface," which intentionally privileges physically gifted people at the expense of those who are less physically talented. The approach is inspired by the methods of feminism, which are designed to identify and criticise systematic inequalities.

Below, we first make the argument that contemporary technology, designed by 'nerds', serves the interests of nerds far better than their traditional enemy, the 'jock' [1]. We introduce critical design as a methodology for both understanding and protesting against such perceived inequality. We briefly discuss contemporary methods for expressing preferences, opinions and strength of feeling, before describing the design and implementation of "the man machine interface," a system designed to allow the expression of preference through physical violence. Subsequently, we discuss the findings of a user study that was carried out to explore the subjective experience of interacting with this device.

\section{Background}

Since the first proto-human picked up a bone club to cave in the skull of his oppressor [2], tools have often been used by the physically weak to subjugate the strong. Just as David slew Goliath through his covert use of technology, modern technology disempowers honest strength in favour of (wordy) obscurantism. Further, it is apparent that today's systems of symbolic manipulation have allowed a disconnect to develop between work and value, allowing the subjugation of the most physically able. Staggering sums of money (c.f. work) can be manipulated by a few clicks or the effortless swipe over a tablet's surface. There is no feedback that relates to the physical consequences of such casual gesture.

"Written words destroy memory and weaken the mind, relieving it of work that makes it strong... They are an inhuman thing." Socrates (in Plato's Phaedrus)

In general, a system develops to benefit those who develop the system [3]. Modern society functions through mechanisms put in place by successive generations of bureaucrats whose chief skills are in the manipulation of symbolic information. Those best able to engage with these semiotic mechanisms will naturally flourish and be promoted to positions whereby they can strengthen the same system by which they were valued in the first place. A runaway process of natural selection has occurred with systems of governance becoming ever more bloated and the majority of populace ever more distant from the policy makers [4].

Computing technology is an essential component of the systems through which the modern world is governed. There is fundamental digital mediation in almost all aspects of our experience, from work, to education, health care, play, socializing, and government. Indeed, much discussion has taken place recently on the consequences, both intended and unintended, and both potential and already realised, of delegating decisions and responsibility to technology [5]. It is beyond question that computing technology serves to perpetuate and promote societal inequalities. However, the idea 
of technological determinism; that a society is solely a product of its enabling technology [6], is a fallacy. Digital computers have the capacity to deploy any number of systems, and have no requirement to benefit any particular group. So, the values designed into computing technology - either deliberately, or by default - do not necessarily need to conform to any present set of agreed upon social norms. Instead, technology can, and should, react against the status quo and provoke the development of new values and morals.

As feminism has provided a lens on the gender inequalities in society, and the often tacit discrimination that occurs through the unquestioning implementation of systems within a specific set of norms [7]; we draw inspiration from these ideas to develop work which can benefit those currently disenfranchised by the disempowerment of strength $[8,9,10]$.

\section{Critical Design}

This project should be considered an instance of critical design; a theoretical approach to design that is intended to provoke deeper thought about the values inherent, but not necessarily obvious, in the design of products. Dunne and Raby [11], in introducing the concept of critical design, suggest that all design is ideological and that the design process is informed by values consistent with a specific worldview. Critical design "rejects how things are now as being the only possibility, it provides a critique of the prevailing situation through designs that embody social, cultural, technical and economic values." (p.58). It is, "a way of looking at design and imagining its possibilities beyond the narrow definitions of what is presented through media and in the shops".

Critical design has recently been discussed in HCI research as a means for exploring and criticizing the values inherent in the design of interactive technology $[12,13]$. Examples of critical HCI include the work of Linsay Grace [14], whose critical gameplay project aims to subvert the dominant assumptions in contemporary video game experiences.

The project presented in the current paper should be understood as a feministinspired critique. Our goals in this work mirror that of feminism, in that we are critically examining the status quo of interface design in order to provoke deeper thought about inequalities in how advantageous that technology is to different groups of people, based on their physical or socially constructed characteristics. The use of the phrase man-machine interface is therefore intended to be humorous, provocative and confrontational, in the true spirit of critical design.

The work reported here could also be considered as a form of "values-sensitive design' $[15,16]$, which is a theoretically grounded approach to design that takes account of human values as a specific part of the design process. The concept was introduced by Friedman to illustrate how human values, whether intentional or not, are inherent in the design process and the outputs of that process. Indeed, the role of human values in the design of technology has recently been discussed at length [17]. 


\section{Strength, Society and Interaction Design}

We believe that it is important for society to recognise, accept and learn to deal with, the inherently aggressive and violent nature of the human species. Indeed, recent work in evolutionary biology emphasises that fighting, specifically the use of the hand as a fist, has markedly shaped its evolution [18]. Prof David Carrier discusses this in a recent interview,

"I think there is a lot of resistance - maybe more so among academics than people in general - resistance to the idea that, at some level humans are by nature aggressive animals. I actually think that attitude, and the people who have tried to make the case that we don't have a nature - those people have not served us well..... I think we would be better off if we faced the reality that we have these strong emotions and sometimes they prime us to behave in violent ways. I think if we acknowledged that we'd be better able to prevent violence in future." [19].

If humans are inherently aggressive and violent in nature, the design of interactive technology that allows for the expression of that aggression seems interesting and useful. However, there are few existing interfaces to computer systems based on brute

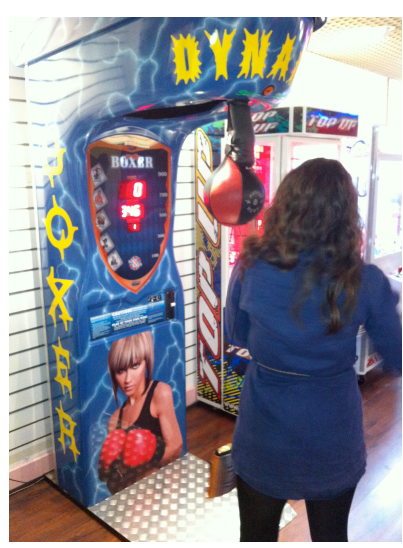

Fig. 1. Amusement Machine physicality $[20,21]$. The traditional 'Test Your Strength' fun fair attraction is the most commonly experienced exception (see Figure 1). Interestingly, Test Your Strength devices provide an opportunity for males to publicly display physical prowess in the context of a vanishing landscape of opportunities for such sexual display. Even though practical reasons for strength are increasingly rare, exaggerated muscle mass is still seen as desirable, though now more likely grown for show, e.g. the 'ripped six-pack' or 'arm guns' commonly on display in nightclubs (i.e. for the purpose of attracting a mate through exaggerated secondary sexual characteristics).

Other notable exceptions, where physical effort have been incorporated into design requirements, include medicine containers which are made deliberately difficult to open (to prevent children from obtaining the contents), and 'fitness' machines where physical exertion is their sole purpose, and although there is much excellent work on exertion based interfaces $[22,23]$, this is specifically not the topic of this paper (which focuses on systemic value bias in interface design).

\section{Expression of Internal Values}

There are many methods used in the social sciences that allow participants to express internal values; opinions, thoughts and feelings (e.g. questionnaires, interviews, forms 
with Likert scales and so on). These methods are all inherently verbal; they require the participant to undertake complex linguistic, or relational, reasoning in order to produce a response that can be used by others when making decisions. The response produced by a participant is typically accepted as a valid measure of that person's opinions, thoughts and feelings, regardless of their relative ease or difficulty in formulating that response. Crucially, those who have greater skill at matching their internal experience with the specific response produced, have greater chance of being understood, and of having their interests acknowledged and represented. It seems interesting to investigate methods through which physically talented people can express opinions with similar finesse.

\section{Measuring Strength of Feeling}

The prototype interface described in this paper, the man-machine interface, provides a novel means for people to express not only their opinions and feelings, but also the strength of those opinions and feelings. The measurement of how strongly people feel (often referred to as valence and arousal measurements) towards a product, service, experience, or concept has a long history where many different approaches have been investigated [24]. As stated above, a commonly used measurement technique is the Likert scale type of questionnaire that allows for an expression of peoples opinion or feelings verbally on a scale between "strongly disagree" and "strongly agree." The man machine interface is presented as an alternative to this linguistic form of measurement, and offers an interesting measure by tapping into base motor responses.

\section{Design}

\section{Conceptual design}

In addition to affording a novel and physically active method of soliciting feedback that may reveal baser truths about a participants' internal state, the design of the system highlights the inherent inequalities in existing methods of feedback and decisionmaking. The system deliberately allows individuals who are able to punch more strongly to have a greater impact on results. This is in contrast to traditional systems of voting in which each individual's vote is valued the same; however, the ability to engage in verbal debate is not equitable and the feelings of the rhetorically weak are often left underrepresented. The interface is designed to facilitate public display of physical prowess (with some targets able to be punched powerfully merely for show). This contrasts with the 'secret-ballot' in which individuals are forced to cloak their representations in the plebiscite veil of the voting booth.

The design of the man machine interface is conceptually simple. A martial arts training aid is used as input for a computer application that allows participants to express opinions. A screen presents participants with questions. Paddles to the left and right of the device (see Figure 5) are used to answer yes/no (or agree/disagree 
etc.) questions. The paddle at the top is used for expressing strength of feeling. All three paddles measure the strength with which participants punched it.

There are some pragmatic considerations in relation to the design. Some people are left-handed some are right-handed. An interface based on punching power therefore needs to be symmetric so as to favour neither. Hence, while binary left/no triggers are suitable for asymmetric distribution (ignoring any cognitive bias), a power measurement is not. Thus the central head target was used to detect power; with the left/right targets used for selection. The character used to ask questions was a bland, nonthreatening automated character (see Figure 6) that would generate little response in and of itself (and early prototypes showed this to be the case). Practically, the automated creation of the animation (based on a text script) allowed the interface dialog to be altered very quickly, which allowed rapid iteration of the design.

\section{Technology}

The system has been adapted from a standard martial arts training aid (a Body Opponent Bag, or BOB). The device selected was the MATT (the Mixed Martial Arts Target Trainer) ${ }^{1}$ and this was selected as it was advertised as being the only home based fitness product capable of simulating the feeling "punching a man's head" (although there are now more products offering this feature of debatable benefit).

Three of the four targets were used (the left and right 'hands' and the 'head'), with the central ('body') target being replaced with a flat screen monitor to provide instruction and feedback to the participants.

USB (Singstar ${ }^{\mathrm{tm}}$ ) microphones were loosely embedded on the back of each target and these were connected to a Raspberry Pi computer for processing.

1 http://www.bayls.co.uk/products/fitness/mmatt-mixed-martial-arts-target-trainer/ 


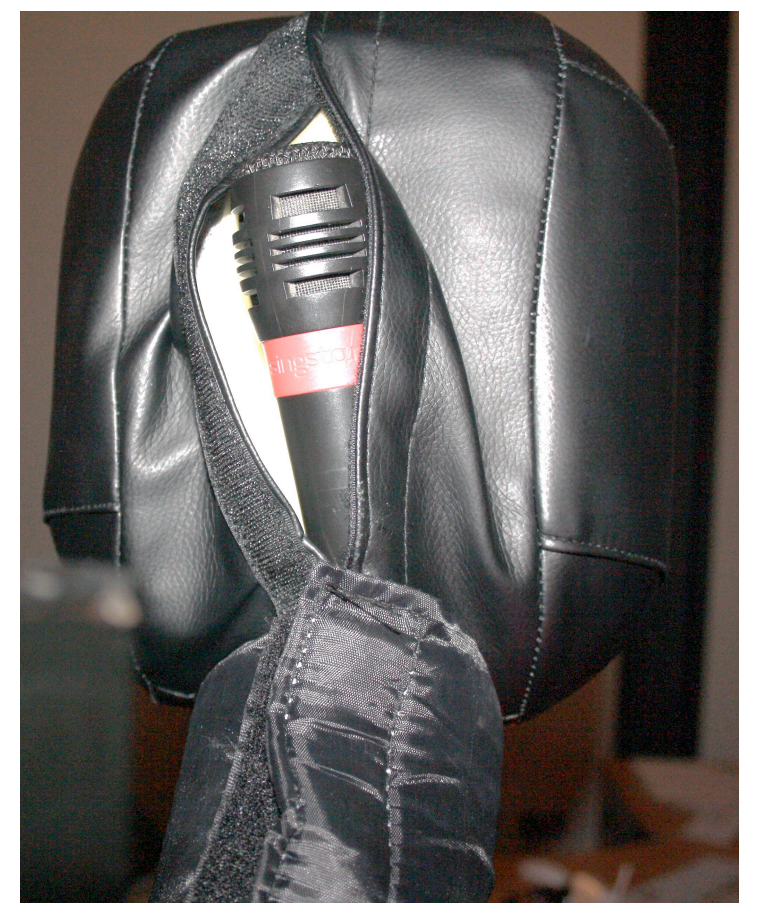

Fig. 2. Main System Components (USB Mic)

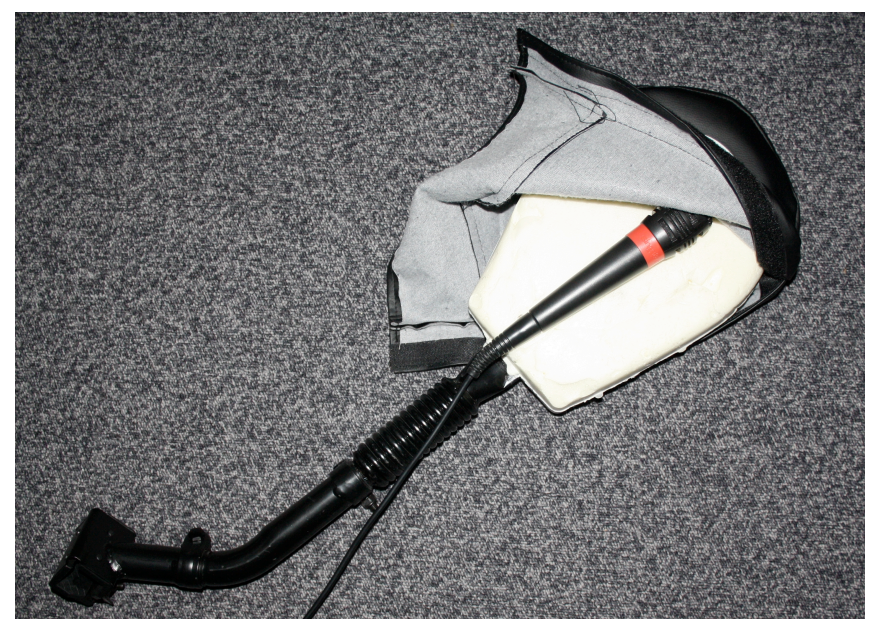

Fig. 3. Main System Components (USB Mic) 


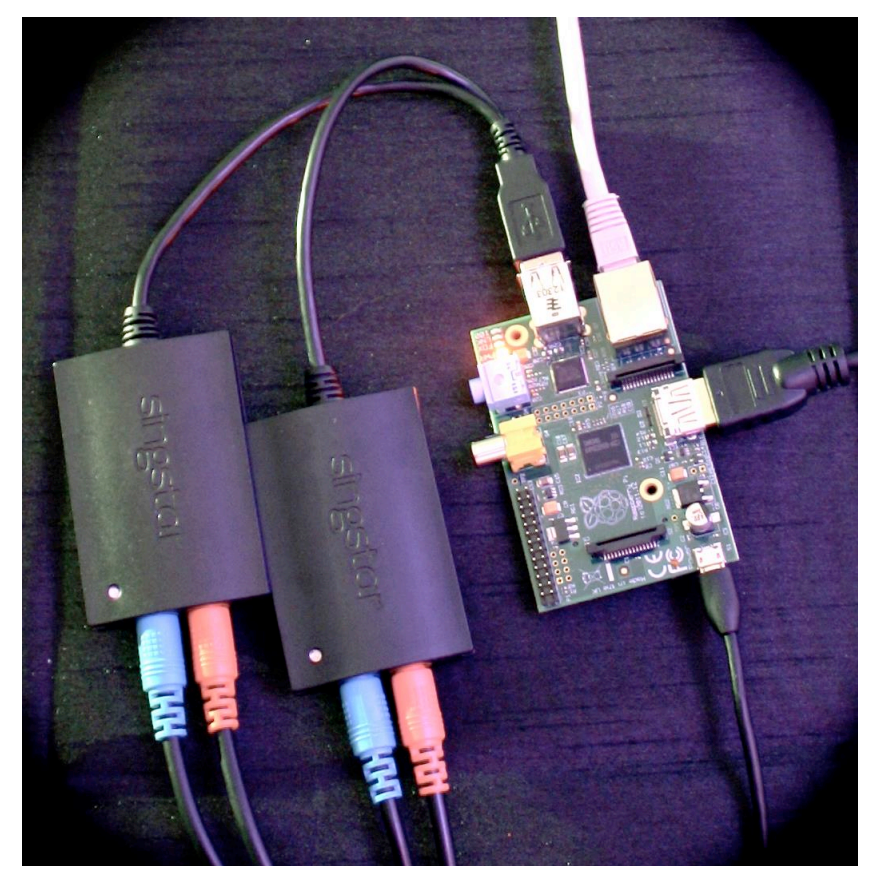

Fig. 4. Main System Component (Raspberry Pi)

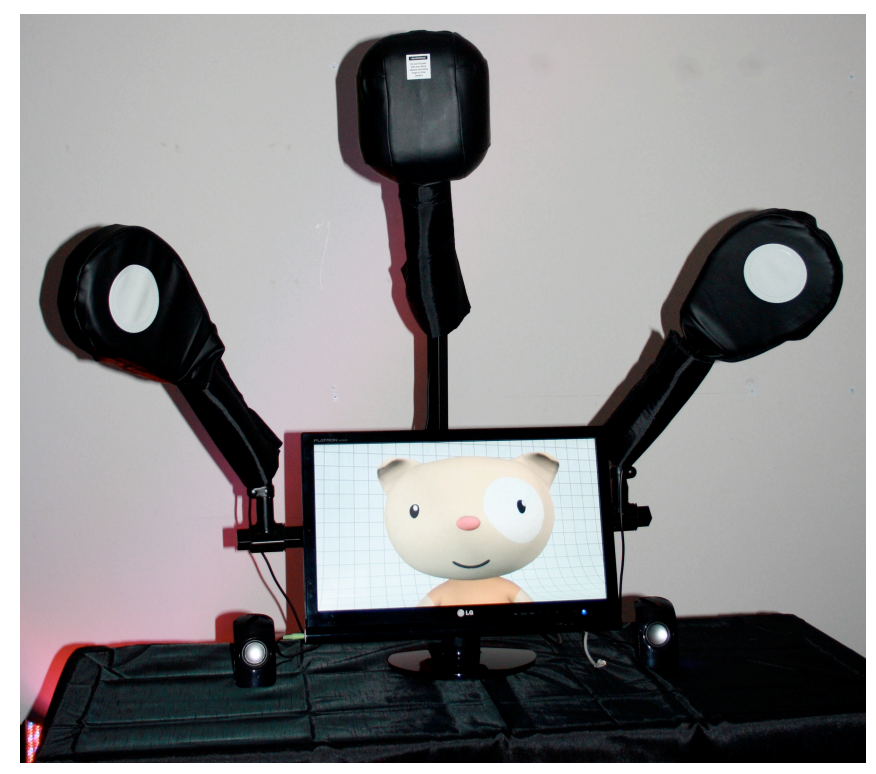

Fig. 5. User's View of the Punchable Interface 
The Raspberry Pi ran a standard Raspbian version of the Linux operating system. A Python script was developed to detect punches (via the RMS of the microphone responses). Punches were recorded to a text file (with volume deemed to approximate the strength of each punch) and used to trigger sound effects (via an external USB speaker) and to start and pause a full screen HD video rendering (oxplayer) of a cute character reading the following instructions.

\section{Instruction Script}

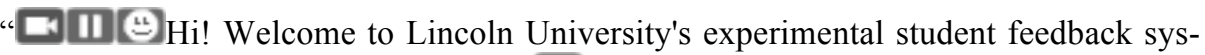
tem. To begin, please enter your ID. II Thanks. Please stand in front of the device and only hit the targets when asked to. OK! Question One. Do you consider this to have been a good module? Please hit either the: "yes" or "no" target now. IINext please indicate the strength of your feelings 1 about this by punching the central head target now. 피 Thanks. Question Two. Do you think that punching things $\mathbb{R}$ is a good way to express your feelings? Please hit the appropriate yes or no target now. II OK! Please indicate the strength of your feelings about this by punching the head. 는 II Thank you and have a nice day. 는 III"

II - Pause and await punch/input

ㄴ. - Joy facial expression (Smile)

- Character points to left or right target

T. Character punches towards the central target

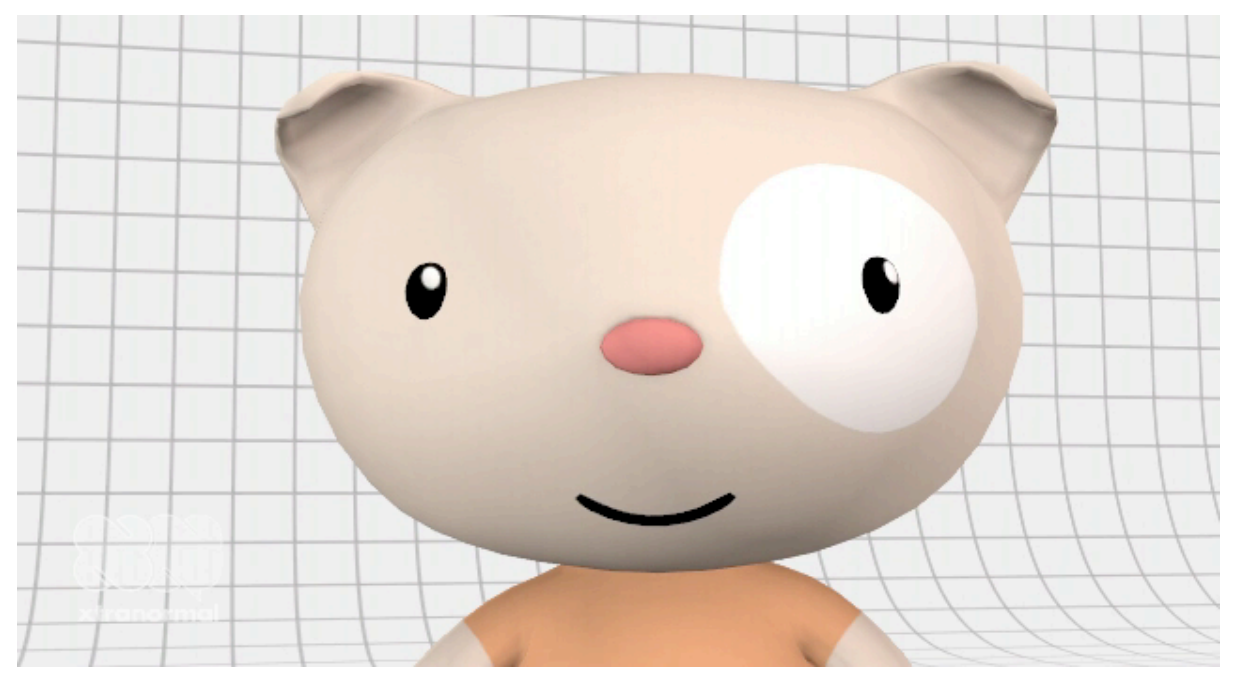

Fig. 6. Interface Character (C) xtranormal.com 2012,2013 (used with permission) 


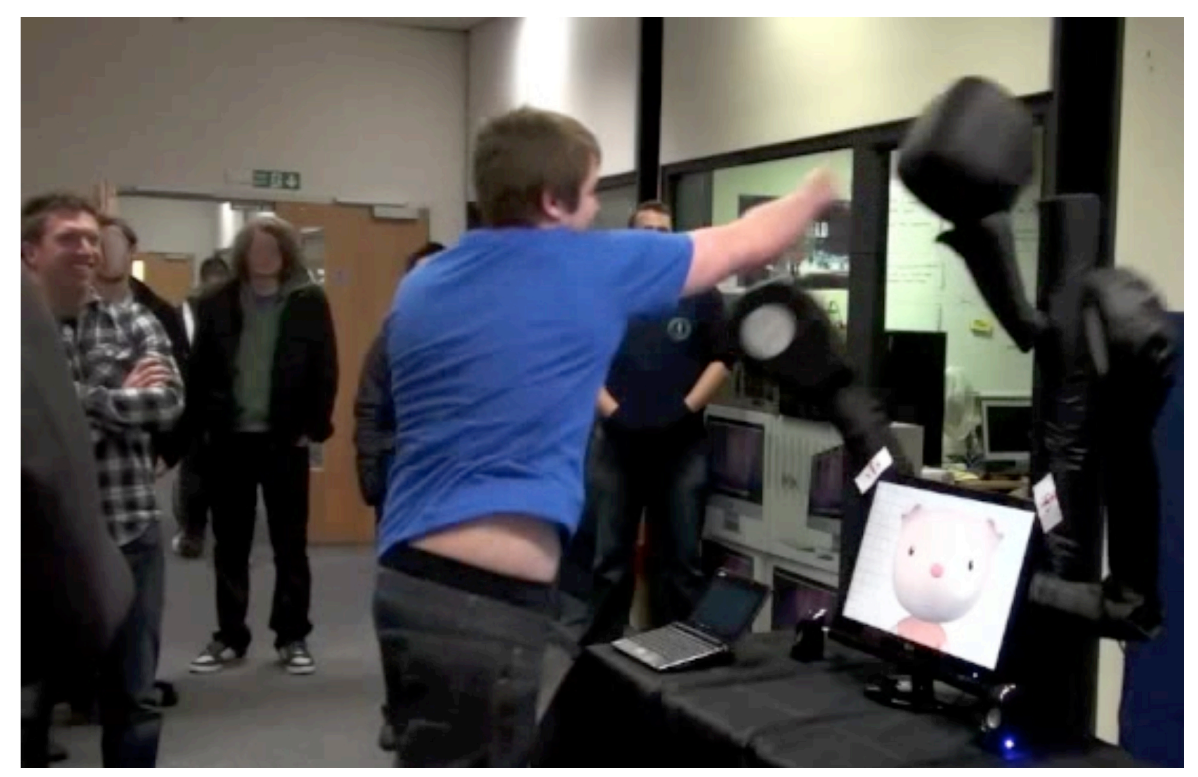

Fig. 7. Punchable Interface Trial

\section{Evaluation}

Thirty potential participants - the entire (all male) undergraduate game design class were asked at the end of the semesters final practical session if they would consider participating in a study relating to interface design. Nine participants, aged 20-23, were recruited and were fully informed as to the purpose of the study and what was required from them. All those who volunteered initially gave written consent to participate and were then asked to fill in a paper-based module evaluation form. This form allows students to anonymously express opinions regarding the quality of that module and is a task routinely undertaken at the end of each module studied. Next, participants were asked to use the interface situated in the Games Computing Lab, one at a time, following the instructions outlined above. Afterwards, two focus groups were conducted in a semi-structured manner, led by the authors. Discussion initially focused on the subjective experience of users engaging with the device, before exploring the concept of expressing "strength of feeling" through "physical strength" and the effects that such a means of expression may have on users, and use, of technology.

\section{Evaluation Plan}

Before reporting the results of focus group discussions, it is important, due to the narrative of the paper, to acknowledge the particular characteristics of the participant sample from which data was gathered. All participants were young males. We may expect such a group to engage readily with competitive activities and opportunities to display physical prowess. Thus, we might expect to find their responses more positive 
and enthusiastic than other groups that we could have sampled. However, participants were also third- and fourth-year computer science students. As such, they are people who have already benefitted from the shift in cultural values away from physical towards linguistic and technological skills, and may expect to continue to do so in future. Due to these potentially conflicting opinions, we believe that they are a particularly interesting group with which to discuss the concept of strength-based interfaces.

Two separate focus groups were convened to discuss the man-machine interface. Group one consisted of five participants and group two consisted of four. Both sessions were audio recorded and those recordings were transcribed for analysis. Group one discussion lasted for approximately one hour; group two lasted for 30 minutes.

\section{Thematic Analysis}

A thematic analysis was conducted on the data recorded from focus groups. Both transcripts were initially read closely by one researcher, who defined a set of eighteen codes. Two researchers then independently applied this coding scheme to the transcripts, before meeting to discuss the fit of the codes to the data. It was agreed that fourteen separate codes were necessary to explain the data gathered. These were collapsed into five overarching themes; expressing strength of feeling via punching, performance, unfairness, politics and punching as an interaction technique. Participants also demonstrated great interest in the novelty of the experience, but this was not deemed sufficiently interesting to discuss below. In addition, we have chosen to omit analysis of the discussion of politics due to space constraints, as there was a huge amount of discussion on this topic.

Punching as an interaction technique. Participants were prompted to discuss whether a punch-based interface would be interesting or useful as a means of controlling computing devices more generally. All participants expressed some interest in this concept, particularly in relation to the frustration commonly experienced by users of interactive technology.

"I mean everyone wants to punch on the computer sometime when it freezes over."

"it would de-stress people. Because if they're getting real stressed at it, [...] maybe if they hit a couple of hits that's it. And then, like a pretty picture of a dog just comes up and just goes,

"Relax." "It's a stress reducing program. Basically, you're taking out on the system."

There were also suggestions for what types of functions the punch interface might be most suitable for controlling, the most common of which was to force quit programs that had crashed. However, there were also other suggestions,

"A super like on facebook,"

"It will fake smash the window, the desktop. If it's basically not working, you can beat the crap out of something until your like really, really relaxed again, and then you start to see more clear with it," 
"It's going to have to have just one outcome when you punch it in per program," "to open up a set program, you can assign it a set program like if you're on Skype, someone is following you, you could just punch something over ten, it would either turn on or turn off,",

"Definitely off."

Expressing Strength of Feeling through Punching. Quite a lot of discussion focused on the opportunity that the device offered people to express the strength of their opinions or feelings via their physical strength. This was seen as novel, and participants expressed both positive and negative reactions to the concept:

Positive. As described in the background section, this project proposes that expressing opinions and feelings via gross physical strength is an activity that may appeal to some people, and for those people may represent a valid means of expression. Participants largely agreed with this concept;

"there's definitely some sort of emotional attachment to something that you punch,"

"there was a lot of emotion behind the punch, so depending on like if you're really strongly for something, and then you punch definitely more power [...] behind it than if you're not for it,"

"If you're angry, you might try and use more force that you [...] normally would." Indeed, one participant bemoaned the lack of existing opportunities to express them self physically;

"I wouldn't like physically hit a person, but if like I was given the action [...] I'd sort of punch something to show how strong I'd feel about something. That was pretty interesting,"

"Having that ability to express how strongly you feel about something is a good way of showing how you're thinking and feeling."

Negative. Participants also expressed some reservations and concerns. Interestingly, most of these focused around the expectations placed on people by a culture that disapproves of aggression;

"Um, I just thought it was just a bit weird. Like, um, like, as a kid, you was taught not to hit anyone or anything. And like constantly, you're getting told that"

"It was like, uh, going against the grain of what I would imagine what most people were told growing up. Like: "Show your emotions by hitting something" isn't usually our primal guidance sort of thing,"

"You could say having young kids punching something could send the wrong message as well as a moral thing, that it's okay to punch things to express yourselves, which isn't really what people go for nowadays?"

Two participants were very negative towards the concept;

"No, I don't like answering with punches,"

"I haven't really got really like a motivation to hit things. So it's like I'd rather just sulk, or something."

There was clearly a good deal of cognitive dissonance provoked through the request to act in a 'violent' way within the confines of a computing laboratory. Even 
though the actions were against martial arts training aids specifically designed for this purpose, this particular group seemed unusually averse to acts of physical expression. This is perhaps to be expected given those activities that would have likely received positive reinforcement through the participants' formative development and training, and, a different group of participants in a different context may well not exhibit such extremes.

Performance. As the session wherein participants interacted with the device took place in public, and classmates were allowed to watch if they wished, there was an element of performance to the behaviour of participants. Participants discussed how they were very conscious of being watched while punching the device;

"It was a little bit weird getting in front of everybody while they was looking at you, punching something,"

and how being watched affected their subjective experience and their actions;

"I mean, you don't want to like, hit really slightly if everyone else is like, smacking it,"

"you don't want to be like the worst person,"

"How am I supposed to react to this properly ... ? ... in a way that won't make me

look like an idiot," "You didn't want it to look like we were weak."

These comments are fascinating in the context of this paper as they underline the disruptive influence of the device. Specifically, this group of people rarely if ever interact with each other in a way that values physical strength. Rather, being an undergraduate computer science cohort, the social hierarchy of most influential or valued members of that group is determined more by their technical skills. The device provided a disruptive influence on the established pecking order and provided the opportunity for physicality-based sexual display.

Reliability. The majority of participants expressed concerns over the reliability of measurements taken by the interface;

"each person is built differently, skill wise. One person might be able to, uh, strongly agree more than another,"

"Yeah, because if it was: "How strongly do you feel about this?" You circle

"Seven" and someone else circles "Seven." If they both punch it [.....] thinking about "Seven" [...] the forces will be different," "The body type of everybody is completely different,"

"It's completely inaccurate."

These comments are interesting, since the interface was designed intentionally to advantage stronger people. Participants identified this inequality, but it did not provoke them, as intended, to think more critically about similar inequalities inherent in other types of input device.

Some participants pointed out problems with reliability of measurement by identifying factors that could affect the strength of punch recorded, but which are not related to strength of emotion or opinion. These include punching technique, 
" a lot of people would do like a typical movie punch and just swing from the side, [...] where as I do [...] a straight sort of punch, which generally gets more power. So, [...] I think from that I might feel strongly about something more so than someone else,"

or confidence,

"Not even the physical size, just like more confident in yourself. You get up and don't care if those people watch you, then you're going to do what you're going to do," "if you get people that aren't confident standing in front of other people, [...] even if they are very strong, they're still going to be really, really reserved."

Participants also suggested means for remedying the unreliability of the interface. Specifically, they suggested taking baseline readings for every user,

"You'd have to look at baseline," "You have like a frame of reference. Everyone's working then on the same kind of relevant level," "Unless, of course, like, the second part was like I saw, a mini-baseline hits, because people are bound to hit either "Yes," and punch it really hard," "Or hit " $X$ " amount of between zero and ten times."

Indeed, the researchers had to repeatedly steer discussion away from implementation of baselines and how they could be implemented. This insistence on fairness across participants is very interesting.

Unfairness of the interface. Most participants expressed some concerns over general "unfairness" inherent in a device that uses physical strength as an input technique. These concerns came in two forms; the first addressed reliability of measurement across individuals, the second focused on the potentially discriminatory effects of this type of input mechanism on those people who use it. Disappointingly none of the groups seemed willing to accept that these biases were a deliberate aspect of the design, and were largely blind to the inherent inequalities in existing systems of societal operation. It seems that participants had difficulty considering the meaning of the design. Given time and opportunity for greater reflection and discussion it is possible that deeper insights may have emerged (though again, results from this idiosyncratic participant pool may not generalise well).

Discrimination. Participants were asked to consider a situation where decisions would be made, whether at university, in national elections, or in government, based on the data gathered from a strength-based interface. They were asked to consider the consequences that this would have on the people that those decisions affected. Participants almost unanimously expressed outrage and sympathy on the part of less physically gifted people.

"It would put everybody else completely out. Everyone that's above a certain age that can't punch as hard as you is then completely cast aside,"

"You could ostracize everyone apart from a small portion of people,"

"If you're, for example, an elderly person, you might not be able to hit it as hard,"

"being rather short myself, it was ... I had to kind of reach a bit further than I would have really liked to." 
Again, while participants identified and discussed the inherent discrimination in the punch interface system, there was little evidence of further thought around existing inequalities perpetuated by other types of systems, whether technological, political or social.

\section{Conclusion}

The expression of physical force is a natural aspect of human behaviour. This study provides an initial exploration of violent force as an input mechanic to interactive technology (tapping into emotions and providing an outlet for pent up aggression). It seems that punching is an interesting interaction technique, enabling responses to be collected based on momentary expression of explosive power. The system reliably detected punches of various strengths, and although more sophisticated measuring devices could make the measurement of force more accurate, in terms of this initial enquiry the correlation with volume proved to be accurate enough.

Participants in the current study demonstrated an ability to effectively control the strength of their punches. They also demonstrated, and reported, significant individual differences in base level of strength, skill in punching, and reaction to the public test situation. The design of the system sought to make use of these differences to provoke discussion relating to the inequalities in other systems. There was clearly a good deal of cognitive dissonance in the group caused by this request and the activity of behaving in a 'violent' manner in a computer lab, there are several aspects to this.

Firstly, we found indications that social conditioning undermines tendencies towards violence in social situations. Participants reported being taught by parents from a young age that violence is not appropriate, particularly as a means of expression. Secondly, the group was highly sensitive to disturbances of the status quo. This included threats to their position within the group hierarchy (through embarrassment or lack of ability). Thirdly, participants were concerned with notions of fairness. Many of the objections to the interface sought to rectify, or reinstate existing bias (e.g. by calculating power relative to a base line). The findings that participants naturally (and unknowingly) wish to reinstate bias that benefits themselves is broadly as predicted, and is coherent in terms of the initial assertions regarding the development of societal structures.

In summary, this study constitutes an initial exploration of violent force as an interaction style for interactive technology. It also examines violent force as a means for expressing thoughts and feelings. While participants reported enjoyment at interacting with the device, they also expressed reservations about the social acceptability of behaving in violent ways. In addition, while participants recognised that the interface was not fairly designed, there was very little evidence that it provoked critical insight on the inherent inequalities in existing systems of societal operation. We intend, in future studies, to explore further the critical potential of violent interaction.

\section{References}


1. Gilsdorf, E., "Geek Pride: Jocks vs. Nerds, Brawn vs. Brain, Hunks vs. Dweebs", in Psychology Today, Retrieved 7 Jan 2013 http://www.psychologytoday.com/blog/geek-pride/201009/jocks-vs-nerds-brawnvs-brain-hunks-vs-dweebs, September 25 (2010)

2. Kubrick, S. and Clarke, A. C., "2001: A Space Odyssey" (Screenplay), (1968)

3. Wallerstein, I., "The Capitalist World-Economy". Cambridge: Cambridge University Press., (1979)

4. Garry, P., "The meaning of big government". Renew America. Retrieved 7 Jan 2013, http://www.renewamerica.com/analysis/garry/110614 (2011)

5. Rushkoff, D. "Present Shock: When Everything Happens Now", Current Hardcover, ISBN-13: 978-1591844761, (2013)

6. Levy, Steven, "Hackers: Heros of the Computer Revolution", Penguin, ISBN13: 978-0141000510 (2002)

7. Hooks, B., "Feminist Theory: From Margin to Center", Eds.2, Pluto Press, 2000

8. Harrington G. S. and Farias S. T., "Sex differences in language processing: functional MRI methodological considerations", J Magn Reson Imaging. Jun; 27(6):1221-8. doi: 10.1002/jmri.21374. (2008)

9. Fine, C. "Delusions of Gender: How Our Minds, Society, and Neurosexism Create Difference" (1st ed.). W. W. Norton \& Company. ISBN 978-0-393-06838$2,(2010)$

10. Jordan-Young, R., "Brain Storm: The Flaws in the Science of Sex Differences", Harvard University Press. ISBN 978-0-674-05730-2. (2010)

11. Dunne, A. and Raby, F., "Design Noir: The secret life of electronic objects". Berlin: Berkhauser, (2001)

12. Bardzell, J., "Interaction Criticism and Aesthetics", In Proceedings of ACM CHI, 2357-2366, (2009)

13. Blythe, M.A. The digital music box: using cultural and critical theory to inform design. In Proceedings of ACM CHI Extended Abstracts, 2297-2302, (2007)

14. Grace, L.,"Creating Critical Gameplay Design". In Proceedings of ACE (2010)

15. Cockton, G., "A development framework for value-centred design". In CHI '05

Extended Abstracts on Human Factors in Computing Systems (CHI EA '05).

ACM, New York, NY, USA, 1292-1295. (2005)

16. Friedman, B. "Value-sensitive design". Interactions 3, 6, 16-23, (1996)

17. Sellen, A., Rogers, Y., Harper, R., and Rodden, T., "Reflecting human values in the digital age". Commun. ACM 52, 3, 58-66, (2009)

18. Morgan, M. H. and Carrier, D. R., "Protective buttressing of the human fist and the evolution of hominin hands", doi: 10.1242/jeb.075713, J Exp Biol 216, 236-244, January 15 (2013)

19. BBC News, "Fighting may have shaped evolution of human hand", Retrieved 7 Jan 2013, "http://www.bbc.co.uk/news/science-environment-20790294, Dec. (2012)

20. Gross, S and Boess, S, "Love Hate Punch", Retrieved 7 Jan 2013, http://v2.nl/archive/works/love-hate-punch, (2010)

21. Nexersys, Retrieved 7 Jan 2013, http://nexersys.com/ (2012) 
22. Mueller, F., "Academic Publications about Exertion Interfaces" Retrieved 7 January 2013, http://exertioninterfaces.com/cms/academic-publications.html 23. Mueller, F, Agamanolis, S, Gibbs, M \& Vetere, F, "Remote Impact: Shadowboxing over a Distance.", CHI'09: Extended Abstracts. Boston, MA, USA. ACM, New York, NY, USA, 3531-3532. (2009)

24. Hazlett, R. L., "Measuring emotional valence during interactive experiences: boys at video game play", In Proceedings of ACM CHI (2006), 1023-1026. 